Chapter 20

\title{
Potentiometry for Study of Supramolecular Recognition Processes Between Uncharged Molecules
}

\author{
Jerzy Radecki and Hanna Radecka \\ Additional information is available at the end of the chapter \\ http://dx.doi.org/10.5772/52803
}

\section{Introduction}

Recently one could observe a continuous increase of scientific interest in host-guest chemistry, and more specifically in the intermolecular recognition processes occurring at liquid-liquid interface $[1-3,7,8]$. The fundamental chemical processes occurring in liquid membrane of potentiometric sensor are guest- induced selective changes in the charge separation across the interface between the liquid membrane and aqueous sample solution. The organic/aqueous interface, often named as "the third phase", possesses unique properties, which are very different from the properties of the bulk phases. In this particular place, many of biological processes of intermolecular recognition occur, demonstrating extremely high selectivity and sensitivity. Numerous instrumental methods were applied for study this phenomenon. Electrochemical one have a significant share in this research.

Potentiometry with using of ion selective electrodes (ISEs) is one of the most popular techniques enable to observe the recognition processes between the ligand and cationic or anionic species occurring in the liquid/liquid interface. The mechanism of potentiometric signal generation relies on the charge separation between two phases, which is the result of a perm selective transfer of analyte ions from the aqueous to the organic phases at the liquid /liquid interface with high sensitivity and selectivity $[9,10]$. This type of sensors have some outstanding advantages including simple design and operation, wide linear dynamic range, relatively fast response and rational selectivity and because of these parameters there are particularly interesting from the perspective of the supramolecular chemist. The potentiometric sensors could be applied as a tool for observation of molecular recognition processes at the border of two phases.

In pioneering paper written by Umezawa and co-workers the possibilities of potentiometric signals generation of polymeric membrane modified with permanently charged ligand such 
as quaternary ammonium salts [4] and lipophilic polyamines [5, 6] after their stimulation with uncharged phenol derivatives were described the first time. According to authors the mechanism of signal generation by membrane modified with quaternary ammonium salts consist of two processes.

First is the complexation of extracted $\mathrm{ArOH}$ and $\mathrm{Q}^{+} \mathrm{X}^{-}$leading to a net movement of anionic species $\left(X^{-}\right)$from the aqueous to the membrane phase. In second step there is proton dissociation of complexed $\mathrm{ArOH}$ and simultaneous ejection of $\mathrm{HX}$ to aqueous phase, involving a net movement of cationic species $\left(\mathrm{H}^{+}\right)$from membrane to the aqueous phase [4].

Being inspired by this paper, we have done systematic study on potentiometric signals generated by membranes modified with electrically neutral host molecules and stimulated with uncharged guest molecules [11-25].

As a receptors (host) molecules for recognition of uncharged phenol derivatives, corroles, calix[4]pyrroles, calix[4]phyrins and metalloporphyrines we have applied. Whereas, for recognition of unprotonated aniline derivatives we have used: $p$-tert-butylthiacalix[4]arene (BTC[4]ene), tetrabromodialkoxythiacalix[4]arene (BATC[4]ene), tetra-undecylcalix[4]resorcinarene (UDC[4]Rene), tetra-undecyl-tetra- $p$-nitrophenylazocalix[4]resorcinarene (UDAC[4]Rene), tetra-undecyl-tetra-hydroxycalix[4]resorcinarene (UDHC[4]Rene), tetraundecyl-tetra-bromocalix[4]resorcinarene (UDBC[4]Rene.

\section{Potentiometric response of tetrapyrrolic macrocyclic compounds liquid membrane electrode towards neutral chloro- and nitrophenols}

The calix[4]pyrroles, calix[4]phyrins and corroles are tetrapyrrolic macrocyclic compounds. All of them belong to very large group of porphyrin analogs and they are well known as sensitive and selective receptors for anions [26-32].

The main differences between corroles, calix[4]pyrroles and calix[4]phyrins are the following. The corroles are almost planar, aromatic macrocycles. Imine nitrogen atoms from the corrole cavity can be protonated at low $\mathrm{pH}[33-36]$.

This is not expected in the case of calix[4]pyrrole and calix[4]phyrins. The calix[4]phyrins (porphodimethenes) demonstrate partly conjugated character similar to porphyrins and partly the non conjugated character of calix[4]pyrroles. Calix[4]pyrroles possess in their structure the relatively dip cavity $[26,32]$. Only the individual pyrroles rings have some aromatic character.

Figure 1 illustrates the structures of calix[4]pyrroles, calix[4]phyrins and corroles being applied for this research.

In Table 1 the values of responses of membrane modified with particular host molecules after stimulation with nitrophenols derivatives are collected. 


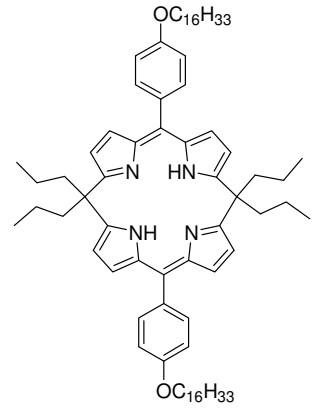

Calix[4]phyrin

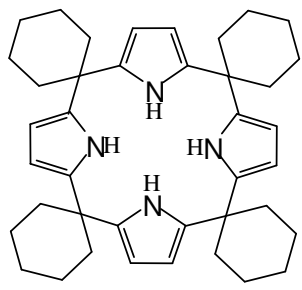

Calix[4]pyrrole

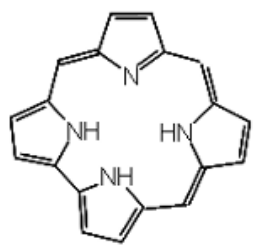

Corrole

Figure 1. The structure of pyrrole hosts.

The results presented indicate that generally, the membrane incorporating calix[4]pyrrole generated the higher potential changes after stimulation with nitrophenols in comparison to calix[4]phyrin and the corrole-containing membrane.

\begin{tabular}{|c|c|c|c|c|c|c|}
\hline \multirow{3}{*}{ Guests } & \multicolumn{6}{|c|}{$\Delta E M F=E M F_{0}-E M F_{f}{ }^{*}$} \\
\hline & \multicolumn{2}{|c|}{ Calix[4]pyrrole } & \multicolumn{2}{|c|}{ Calix[4]phyrin } & \multicolumn{2}{|c|}{ Corrole } \\
\hline & $\mathrm{pH}=4.0$ & $\mathrm{pH}=6.0$ & $\mathrm{pH}=3.0$ & $\mathrm{pH}=6.0$ & $\mathrm{pH}=3.0$ & $\mathrm{pH}=6.0$ \\
\hline ortho-nitrophenol & -3.0 & -3.0 & $-0,7$ & ---- & -4.3 & -6.0 \\
\hline meta-nitrophenol & -25.9 & -24.0 & $-2,8$ & ---- & -9.7 & -9.9 \\
\hline para-nitrophenol & -25.9 & -35.0 & $-4,1$ & ---- & -14.1 & -10.3 \\
\hline
\end{tabular}

Table 1. The potentiometric responses of $\mathrm{ISE}_{\mathrm{s}}$ incorporating of calix[4]pyrrole, calix[4]phyrin, corrole towards of nitrophenols isomers

The potentiometric signal generated by membranes modified with corrole and calix[4]phyrin and stimulated with nitrophenol derivatives are very week and comparable. In spite of 
significant differences of signal magnitude for each type of membranes, generally all of them displayed the same signal magnitude sequence:

para-nitrophenol $\geq$ meta-nitrophenol > ortho-nitrophenol

This sequence is in good order with the lipophilicity and acidity of the nitrophenolic derivatives (see Table 2)

\begin{tabular}{ccccccc}
\hline \multirow{2}{*}{ Guest compound } & $\mathbf{p K a}$ & Log $\mathbf{P}_{\text {oct }}$ & \multicolumn{5}{c}{ Neutral form [\%] } \\
\cline { 5 - 7 } & & & $\mathbf{p H}=\mathbf{2 . 0}$ & $\mathbf{p H}=\mathbf{4 . 0}$ & $\mathbf{p H = 6 . 0}$ & $\mathbf{p H}=\mathbf{8 . 0}$ \\
\hline Para-nitrophenol & 7.16 & 1.91 & 99.99 & 99.93 & 93.54 & 12.63 \\
\hline Meta-nitrophenol & 8.39 & 2.00 & 99.99 & 99.99 & 99.6 & 71.05 \\
\hline Ortho-nitrophenol & 7.21 & 1.79 & 99.99 & 99.94 & 94.25 & 13.95 \\
\hline 2.4-dinitrophenol & 4.11 & 1.54 & 99.23 & 56.31 & 1.27 & 0.01 \\
\hline 2.5-dinitrophenol & 5.22 & 1.75 & 99.94 & 94.32 & 14.24 & 0.16 \\
\hline 2.6-dinitophenol & 4.15 & 1.25 & 99.30 & 58.54 & 1.39 & 0.01 \\
\hline
\end{tabular}

Table 2. Acidity and lipophilicity of nitrophenol derivatives. Log $\mathrm{P}_{\text {oct/water }}$ - logarithm of partition coefficient between $\mathrm{n}$ octanol and water $[36,37] \mathrm{pKa}$ - acidity constants $[35,36]$

The weak response of the membranes studied towards ortho-nitrophenol probably is a consequence of formation of an intramolecular hydrogen bond because of adequate closeness of two functional groups $-\mathrm{OH}$ and $-\mathrm{NO}_{2}[14,16]$.

The relationship between the magnitude of the potentiometric response of the polymeric membrane modified with calix[4]pyrrole and the acidity of the undissociated phenolic guests we have although confirmed by the study of isomers of chloro- and fluorophenols [20]. Generally, the sequence of the magnitude of signal generated by discussed phenol derivatives follow their acidity sequence and is as follow:

nitrophenols $>>$ chlorophenols $>>$ fluorophenols

Presented results indicate that the acidity of the guest molecules is one of the most important parameters decisive about quality of potentiometric signal generation by membranes modified with ligands under discussion. An increase of the acidity of guest molecules causes an increase of the potentiometric response. The magnitude sequence of the signal generated by the isomeric chlorophenols was the same as in the case of nitrophenols:

para-chlorophenol >meta-chlorophenol > > ortho-chlorophenol

Again, the response of ortho-chlorophenol was the weakest, because the intermolecular hydrogen bounds formed between $-\mathrm{OH}$ and $-\mathrm{Cl}$ groups hamper the recognition process of host (calix[4]pyrrole ) molecule and guest (ortho-chlorophenol). In consequence this leads to decrease of membrane potential changes [20]. 
Because the potentiometric signals of calix[4]phyrins and corrole modified membranes were very weak towards nitrophenols, the dinitrophenol isomers as strongest acids were selected as the guest molecules [14].

\begin{tabular}{ccccc}
\hline \multirow{2}{*}{ Guests } & \multicolumn{2}{c}{ Calix[4]phyrin } & \multicolumn{2}{c}{ Corrole } \\
\cline { 2 - 5 } & $\mathrm{pH}=3.0$ & $\mathrm{pH}=6.0$ & $\mathrm{pH}=3.0$ & $\mathrm{pH}=6.0$ \\
\hline 2,4-dinitrophenol & -77.1 & -4.7 & -36.2 & -22.8 \\
\hline 2,5-dinitrophenol & -22.2 & -14.9 & -7.8 & -19.6 \\
\hline 2,6-dinitrophenol & -54.6 & -17.3 & -6.1 & -13.1 \\
\hline
\end{tabular}

Table 3. The potentiometric responses of $\mathrm{SE}_{\mathrm{s}}$ incorporating of calix[4]phyrin and corrole towards of dinitrophenol isomers.

The responses of both of investigated membranes towards dinitrophenols were stronger than observed for mono - nitrophenols [14].

The sequence of signal magnitude in account of host molecules was as follow:

calix[4]phyrin> corrole

in account of isomer of dinitrophenol (for calix[4]phyrin host) was as follow:

2.4 -dinitrophenol > 2.6- dinitrophenol > 2.5- dinitrophenol

Again the results obtained support our previous hypothesis that the acidity of target phenol derivatives is crucial for the potentiometric signals of liquid membrane incorporated with host molecules such as calix[4]pyrrole [19], calix[4]phyrin or corrole [14]. The lipophilicity of analytes is rather a secondary parameter. Similar results were reported for polyamines [5, 6, 38-40].

The nitrophenol guests might interact with calix[4]phyrin, corrole or calix[4]pyrrole via "sinking" into the host cavity with the phenolic $\mathrm{OH}$ pointed towards the $\mathrm{NH}$ units of macrocycles. This was confirmed by NMR measurements [14]. Taking into account this mechanism of interaction, we can explain the good correlation between the signal magnitude sequences for all type of membranes and steric hindrance around the $\mathrm{OH}$ group present in guest molecule.

\section{Elucidation of the mechanism of the potentiometric signal generation of calix[4]pyrrole, calix[4]phyrin and corrole-ISEs upon stimulation by undissociated phenol derivatives}

The results we have obtained for calix[4]pyrrole [ 16, 17, 19, 20 ], calix[4]phyrin or corrole [14, 15] modified membranes and the results reported for macrocyclic polyamines [5, 6, 38-40] suggest that the intermolecular recognition processes between the ligands investigated and 
undissociated nitrophenol isomers occurring at the organic/aqueous interface, leading to the potentiometric signal generation, is a general phenomenon.

The results show a higher potentiometric response in all of discussed membranes for the more acidic guest. This fact confirms the influence of the acidity and the lipophilicity of the neutral guest on the signal generation process by membranes incorporating calix[4]phyrin, corrole or calix[4]pyrrole derivatives.

A comparison of the results for investigated host molecules shows that calix[4]pyrrole modified membranes are the considerably more sensitive towards phenolic guests that the calix [4]phyrin or corrole [15, 17, 19]. While calix[4]pyrrole, calix[4]phyrin and corrole modified membranes do not respond towards the dissociated form of phenol derivatives, the polyamine modified membranes do respond [38-40].

Investigated membranes displayed the signal magnitude sequence as follow:

calix[4]pyrrole >calix[4]phyrin > corrole

The generation of membrane potential changes after stimulation with undissociated isomers of phenols derivatives could be explained as follows. In the first step, a supramolecular complex between the host molecules located at the surface of liquid membrane phase, and the neutral phenol guest placed at the surface of the aqueous phase is formed. This interaction relays on the hydrogen bond creation between the $\mathrm{OH}$ group of nitrophenol and pyrrole $\mathrm{NH}$ groups from the macrocyclic hosts. This was proved by NMR measurements [14].

The formation of such a supramolecular complex, according to mesomeric and inductive effects, causes an increase of acidity of the phenol $\mathrm{OH}$ function. This may decrease the $\mathrm{pK}_{\mathrm{a}}$ of the phenol derivatives at the surface of the polymeric phase. This leads to the dissociation of $\mathrm{OH}$ group and finally to proton ejection from the interface to the aqueous layer adjacent to the organic phase. The energy gained from the proton solvation process is probably the driving force allowing for the dissociation of phenol derivatives at the aqueous/organic membrane interface. This event is responsible for the generation of an anionic response of calix[4]pyrrole, calix[4]phyrin and corrole incorporating membranes after their stimulation with undissociated phenols.

$\mathrm{ArOH}_{(\mathrm{aq})} \leftrightarrow \mathrm{ArOH}_{(\mathrm{mem})}$ extraction (i)

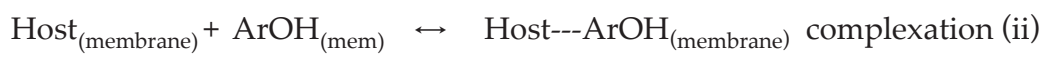

Host--- $\mathrm{ArOH}_{\text {(membrane) }} \leftrightarrow \mathrm{Host}^{---} \mathrm{ArO}^{-}+\mathrm{H}^{+}$dissociation and proton ejection to water surface (iii)

The increase of the proton concentration in the very thin aqueous layer containing $1.0 \times 10^{-2} \mathrm{M}$ para-nitrophenol in $1.0 \times 10^{-2} \mathrm{M}$ of $\mathrm{KCl}(\mathrm{pH} 4.0)$, adjacent to the calix[4]pyrrole or corrole membrane surface, supported this assumption [14,17]. According to the mechanism proposed, the lack of the potential changes of calix[4]pyrrole, calix[4]phyrin and corrole ISEs observed in the presence of phenolic guests at alkaline $\mathrm{pH}$ could be explained as follows.

At this $\mathrm{pH}$ the concentration of $\mathrm{OH}^{-}$in the water phase is high enough to block the cavity of all investigated host molecules by creation of host $-\mathrm{OH}^{-}$complex $[14,17]$. Thus, the formation 
of a supramolecular complex with phenolic guests is not possible. To confirm that such complex could block the cavity of the calix[4]pyrrole, in our previous investigation we have tested the membrane modified with a calix[4]pyrrole substituted with bromine atoms at the $\beta$ - carbons. The lack of any response towards nitrophenol isomers of a membrane incorporating bromine derivatives of calix[4]pyrrole, even in strong acid solution supports this assumption [14,17]. The electron withdrawing bromine atoms increase the affinity of calix[4]pyrrole towards $\mathrm{OH}^{-}$. Such a complex could be created even in acidic medium. Therefore, in this case the cavity of calix[4]pyrrole is blocked and the supramolecular ligand - phenol complex based on hydrogen bonds can not be created [14, 17].

The lack of any response of the membrane modified with calix[4]phyrin or corrole towards dinitrophenol isomers and very low response towards nitrophenol isomers in alkaline medium (Table 1) could be explained as follow. The consequence of host-OH - complex creation is the negatively charged surface of polymeric membranes. Dinitrophenols in such circumstances also exist in the anionic forms. Thus, the host-guest electrostatic repulsion force is probably the main reason preventing interaction between them.

The magnitude sequence of the potentiometric signals observed for calix[4]pyrrole, calix[4]phyrin and corrole membranes suggests that the acidity of the target molecules is one of the important factors affecting the process of potentiometric signal generation. A similar relation was observed in the case of macrocyclic polyamine-ISEs [5, 6]. In Table 2 the values of $\mathrm{pK}_{\mathrm{a}}$ and $\log \mathrm{P}_{\text {oct }}$ of target molecules investigated were collected.

On the other hand, the recognition of phenol derivatives by calix[4]pyrrole calix[4]phyrin and corrole is such that guests respectively bury themselves into the host cavity or are perpendicular to the macrocycle, with (in both cases) the phenolic $\mathrm{OH}$ pointed toward the pyrrole end, where the hydrogen bonds with $\mathrm{NH}$ units are formed [14, 17, 42$]$. Because of this, the sensitivity sequences observed for nitrophenol as well dinitrophenol isomers reflect also the magnitude of the steric obstacle, which is the lowest in the case of para-nitrophenol and 2,4-dinitrophenol. Therefore, for these two guests, the strongest potentiometric responses of ISEs studied were observed. A comparison of the results we have obtained for calix[4]pyrrole and [16, 17] calix[4]phyrin and corrole [14, 21, 42] and the results reported for macrocyclic amines [5, 6, 38-40] showed that the potential generation by the membranes modified with nitrogencontaining macrocyclic compounds after stimulation with phenol derivatives is a general phenomenon. The most important parameters governing this phenomenon are the differences between the acidity of the $\mathrm{OH}$ group of the target molecules and the ability of the NH group of the macrocyclic ligands to create the hydrogen bonds with $\mathrm{OH}$ group of the phenol derivatives.

The signal magnitude sequence based on the host molecules incorporated into the membranes is as follows:

polyamines $>$ calix $[4]$ pyrroles $>$ calix $[4]$ phyrins $>$ corroles

This sequence reflects the sequence of availability of hydrogen atoms coming from $\mathrm{NH}$ or $\mathrm{NH}$ ${ }^{+}$group of ligand for $\mathrm{OH}$ group of phenol derivatives. This availability is crucial for host-guest complex creation. 
Calix[4]pyrrole changes its conformation upon complexation of target molecules, and this macrocycle adopts a cone conformation with the four pyrrole $\mathrm{NH}$ groups forming hydrogen bonds with $\mathrm{OH}$ group of phenol derivatives. The similar reorganization of the calix[4]pyrrole cavity upon complexation with halide anions was reported [26, 27, 29]. In the case of corrole, such conformational change is not possible because of its rigid structure [41]. As a consequence a strong four-center hydrogen bond can not be created. This is probably the explanation of the weaker potential signal generated by the membrane modified with corrole stimulated with nitrophenols in comparison to membranes modified with calix[4]pyrrole. This statement is supported by results obtained for membranes modified with protonated macrocyclic polyamines, which because of their highest flexibility and ionic character are able to create the strongest supramolecular complex based on hydrogen bonds [40]. This leads to the strongest polarization of O-H bond of phenol derivatives. Such membranes generated the strongest signal for nitrophenol derivatives and only these types of membranes are able to recognize dihydroxybenzene isomers, which are very weak acids $[6,40]$. The relationship between acid -base properties of guest is in good agreement with the proposed mechanism. The dissociation of the O-H group at the liquid /liquid interface from the phenol - ligand complex is necessary for the generation of membrane potential changes. In the case of macrocyclic polyamines, the hydrogen bond between the $\mathrm{N}-\mathrm{H}$ and $\mathrm{OH}$ phenolic group is the strongest, and as a consequence, this causes the highest increase of the acidity of proton from -OH. In the case of calix[4]pyrrole and corroles, the hydrogen bonds are weaker than macrocyclic polyamines. Therefore, the increase of the acidity of $\mathrm{OH}$ group from phenolic guest upon creation of supramolecular complexes with calix[4]pyrrole and corrole are lower in the comparison to this observed for polyamines.

The response properties of ISEs based on ion carriers are strongly influenced by the membrane composition, in particular by the presence of ionic sites in the organic membrane [44-46]. The type of ionic sites depends on the charge of ionophore. In the case of ISEs based on neutral host molecules, ionic sites with the charged sign opposite to that of primary ions are necessary to obtain a Nernstian response, to decrease the membrane resistance, to reduce the ion interference, and to improve the detection limit and selectivity. On the other hand, in ISEs based on electrically charged host, ionic sites with the same charge sign as the primary ions are recommended. In case of potentiometric sensors destined for the detection of neutral compounds there is no general knowledge about the influence of ionic sites on response property.

The calix[4]pyrroles are neutral molecules. On the contrary, the corroles could exist in the three forms: cationic, neutral or anionic [32]. Therefore, two types of ionic sites (anionic and cationic) were used for additional modification of liquid membrane electrodes incorporating both hosts.

The membranes containing corrole and lipophilic cationic salt, tridodecylmethyl -ammonium chloride (T-DDMACl), demonstrated a better sensitivity and a wider dynamic range of potentiometric response towards mono- and dinitrophenol isomers in comparison to membranes containing only corrole [14]. On the other hand, the corrole membranes additionally incorporating an anionic lipophilic salt, potassium tetrakis(p-chlorophenyl)borate (K-TpCPB), gave no response towards phenolic guests. 
A similar influence of both type of lipophilic salts were observed for calix[4]pyrrole liquid membrane electrodes [17].

The addition of a lipophilic anion-exchanger into calix[4]pyrrole or corrole-incorporating membranes induces the increase of their $\mathrm{pH}$ and phenol response.

This supports the hypothesis, that in the mechanism of their potentiometric response towards $\mathrm{pH}$ or phenol derivatives, the reversible hydroxide transport form aqueous to organic phase is involved [17].

\section{Potentiometric responses of $\mathrm{Mn}(\mathrm{III})$-porphyrin and dipyrromethene $\mathrm{Cu}(\mathrm{II})$ containing sensors toward paracetamol}

The potentiometric responses of these sensors toward paracetamol were measured in $0.01 \mathrm{M}$ phosphate buffer at $\mathrm{pH}=5.5$ [22]. Under these conditions, paracetamol $(\mathrm{pKa}=9.5)$ exists as the undissociated compound in solution. The polymeric liquid membrane and carbon paste based sensor were tested toward paracetamol. Both of the sensors contain $\mathrm{Mn}$ (III)-porphyrin as the host molecule.

The generation of membrane potential changes after stimulation with undissociated paracetamol molecules could be explained as follows. In the first step, chloride ligated Mn(III)porphyrin creates an aqua-complex via simple binding of water as a sixth ligand. The creation of such a complex was described by Meyerhoff et al. [47]:

$$
\begin{gathered}
\mathrm{Mn}(\mathrm{TPP}) \mathrm{Cl}+\mathrm{H}_{2} \mathrm{O} \leftrightarrow \mathrm{Mn}(\mathrm{TPP}) \mathrm{ClH}_{2} \mathrm{O} \\
\mathrm{Mn}(\mathrm{TPP}) \mathrm{ClH}_{2} \mathrm{O}+\text { paracetamol } \leftrightarrow \mathrm{Mn}(\mathrm{TPP}) \mathrm{ClH}_{2} \mathrm{O} \text {---paracetamol } \\
\mathrm{Mn}(\mathrm{TPP}) \mathrm{Cl} \text {---paracetamol complexation }+\mathrm{H}_{2} \mathrm{O} \\
\mathrm{Mn}(\mathrm{TPP}) \mathrm{Cl}-- \text {-paracetamol } \leftrightarrow \quad \mathrm{Mn}(\mathrm{TPP}) \mathrm{Cl}-- \text {-paracetamol }{ }^{-}+\mathrm{H}^{+} \\
\text {dissociation of paracetamol and ejection of proton to water phases }
\end{gathered}
$$

In the next step, a second-sphere supramolecular complex of paracetamol molecules with $\mathrm{Mn}(\mathrm{TPP}) \mathrm{ClH}_{2} \mathrm{O}$ is created. The existence of such a complex at the surface of a polymeric liquid membrane modified with metalloporphyrins was postulated by Kibbey et al. [48]. This secondsphere interaction with paracetamol molecules occurs probably at a low sample concentration. When the concentration of paracetamol increases, an exchange of second-sphere coordinated paracetamol for inner-sphere water ligands occurs, and, as a consequence, a complex between the $\mathrm{Mn}(\mathrm{III})$ centers and paracetamol, via the oxygen atom from the amide group is created. 
In the measuring condition ( $\mathrm{pH}=5.5)$, paracetamol molecules exists in undissociated form $\left(\mathrm{pK}_{\mathrm{a}}=9.5\right)$. The formation of the above mentioned complex, according to a combination of mesomeric and inductive effects, causes an increase of the acidity of the phenolic $\mathrm{OH}$ function from paracetamol molecule. As a consequence, this leads to a more facile dissociation of the $\mathrm{OH}$ group and finally to $\mathrm{H}^{+}$ejection from the interface to the aqueous layer adjacent to the organic phase.

This event is responsible for the generation of an anionic response of the polymeric liquid membranes modified with metalloporphyrins after their stimulation with undissociated paracetamol.

The reaction of the metalloporphyrin complex with paracetamol was confirmed by spectroscopic measurements at the border between water and the polymeric membrane. The UV-Vis absorption spectrum of a thin membrane film containing $\mathrm{Mn}(\mathrm{III})$-porphyrin deposited onto glass slides conditioned in $0.01 \mathrm{M}$ phosphate buffer solution $(\mathrm{pH}=5.5)$ exhibited one main band at $470 \mathrm{~nm}$ and two weaker bands at 376 and $400 \mathrm{~nm}$. After conditioning in phosphate buffer with an increasing concentration of paracetamol, the absorbance maximum decreased and shifted to shorter wavelength. This blue shift was expected due to the increase in electron density around the $\mathrm{Mn}(\mathrm{III})$ centers by the coordinated amide. These data confirm the creation of a complex between the Mn(III)-porphyrin and paracetamol [22].

The electrochemically active $\mathrm{Cu}$ (II) dipyrromethene complex immobilized on the surface of gold electrodes previously modified with a dodecanethiol monolayer was successfully applied for voltammetric determination of paracetamol [23]. The interaction of paracetamol with $\mathrm{Cu}$ (II) redox centers was a base of analytical signal generation. The presence of human plasma in the measuring solution influence very little on the sensor performance. Its linear dynamic range (0.2-3.2 mM) was sufficient for controlling the toxic level of paracetamol in human plasma [23].

\section{Potentiometric response of membranes modified with undecylcalix[4] - resorcinarene derivatives towards of unprotonated diaminobenzene isomers}

According to presented mechanism of anionic potentiometric signal generation by membranes modified with nitrogen containing macromolecules as host molecules and stimulated with neutral form of phenol derivatives the crucial phenomenon is transfer of protons from the membrane surface to surface of water phase. From this point of view it was logical and interesting to check if generation of cationic potentiometric signal by membranes modified with macrocycles containing the phenolic group stimulated with unprotonated derivatives of aniline would be possible $[25,52]$

There are summarization of systematic research results of the intermolecular recognition processes at the water/polymer membrane border between some derivatives of undecylcalix[4]resorcinarene (Figure 2) and neutral (unprotonated) forms of aniline and its derivatives 
such as: aminoaniline, chloroaniline, hydroxyaniline, methylaniline, methoxyaniline and nitroaniline obtained with using potentiometry.

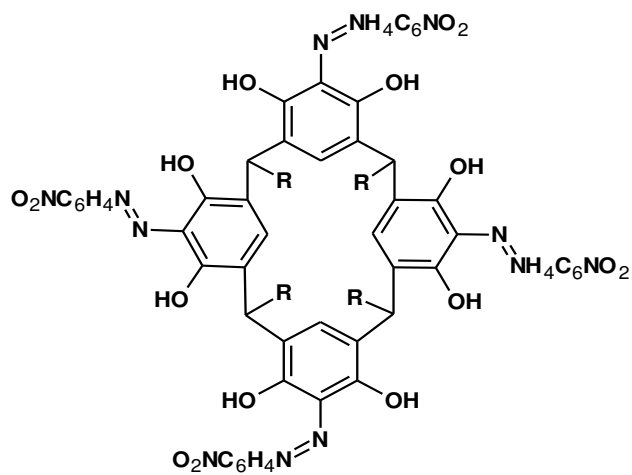

Ligand 1

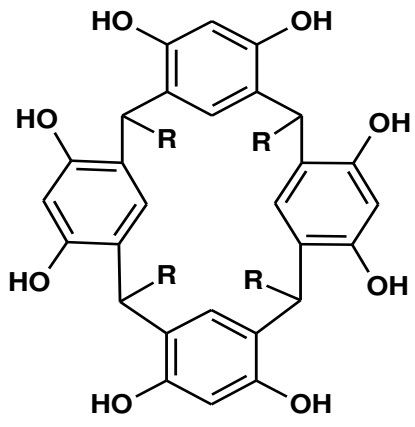

Ligand 2

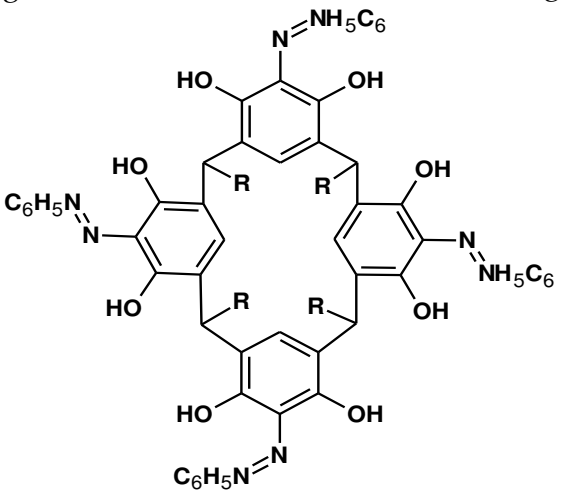

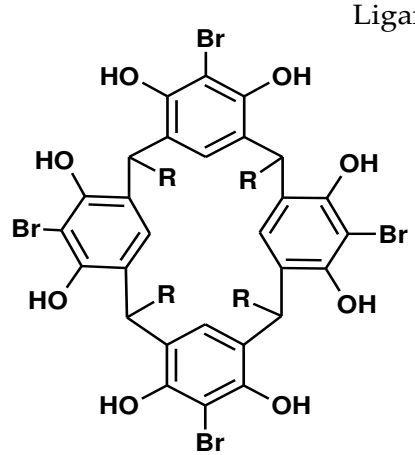

Ligand 4

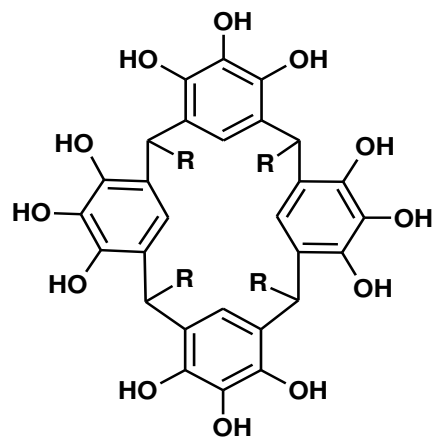

Ligand 5

Figure 2. The structure of host molecules. 
In Table 4 the values of potentiometric response of PVC supported liquid membranes incorporated with calixarene host generated in the presence of aniline derivatives are collected. The measurements for all membranes studied were done at $\mathrm{pH}$ 7. At this $\mathrm{pH}$ investigated aniline derivatives exist in water almost entirely as neutral (unprotonated) compounds (see Table 5).

As it is seen from results introduced from Table 4, all types of membranes generate cationic response towards aniline derivatives

\begin{tabular}{|c|c|c|c|c|c|c|c|}
\hline Guests & $\mathrm{pK}_{1}$ & $\log P_{o / w}$ & $\begin{array}{c}\Delta \mathrm{E}[\mathrm{mV}] \\
\text { Lig } 1\end{array}$ & $\begin{array}{c}\Delta \mathrm{E}[\mathrm{mV}] \\
\operatorname{Lig} 2\end{array}$ & $\begin{array}{c}\Delta E[m V] \\
\text { Lig } 3\end{array}$ & $\begin{array}{c}\Delta \mathrm{E}[\mathrm{mV}] \\
\text { Lig } 4\end{array}$ & $\begin{array}{c}\Delta E[m V] \\
\text { Lig } 5\end{array}$ \\
\hline p-aminoaniline & 6.22 & -0.26 & 148.9 & 138.4 & 88,4 & 86.9 & 41.5 \\
\hline$p$-anisidine & 5.36 & 1.15 & 118.6 & 68.9 & 53,9 & 59.4 & 37.4 \\
\hline$m$-anisidine & 4.20 & 1.32 & 92.6 & 62.2 & 55,1 & 20.1 & 28.4 \\
\hline o-aminoaniline & 4.61 & 0.37 & 66.8 & 57.2 & 64,2 & 31.0 & 31.5 \\
\hline m-aminoaniline & 5.01 & 0.03 & 36.2 & 42.1 & 35,8 & 13.8 & 7.6 \\
\hline$p$-toluidine & 5.08 & 1.43 & 92.3 & 36.2 & 44.1 & 27.0 & 30.2 \\
\hline p-chloroaniline & 3.98 & 1.81 & 31.5 & 24.2 & 22,8 & -0.6 & 6.2 \\
\hline o-anisidine & 4.53 & 1.65 & 62.7 & 20.1 & 35,7 & 19.8 & 7.8 \\
\hline p-hydroxyaniline & 5.48 & -0.24 & 27.6 & 15.5 & 25,2 & -2.1 & 2.4 \\
\hline aniline & 4.87 & 1.24 & 57.7 & 12.8 & 34,5 & 10.7 & 13.1 \\
\hline$m$-toluidine & 4.71 & 1.59 & 84.2 & 9.7 & 32,9 & 14.9 & 22.0 \\
\hline o-toluidine & 4.45 & 1.61 & 75.8 & 9.4 & 20,8 & 10.7 & 7.7 \\
\hline p-nitroaniline & 1.02 & 1.19 & 4.7 & 3.0 & - & - & 2.4 \\
\hline m-chloroaniline & 3.52 & 1.88 & 19.8 & 0.7 & 2 & - & 9.2 \\
\hline o-chloroaniline & 2.66 & 2.02 & 8.6 & -4.5 & 1,2 & - & 1.9 \\
\hline
\end{tabular}

$\Delta E[m V]=E_{0}-E_{i} E_{0}$ - potential recorded in buffer solution, $E_{i}$ - potential record in the presence of analyte at is final concentration

Table 4. Potentiometric response of PVC supported liquid membranes incorporated with host undodecylcalix[4] resorcinarene derivatives generated in the presence of aniline derivatives. Log $\mathrm{P}_{\text {oct/water }}-\operatorname{logarithm}$ of partition coefficient between $n$-octanol and water $[36,37]$ pKa - acidity constants $[35,36]$ 


\begin{tabular}{|c|c|c|c|c|c|}
\hline & \multirow{2}{*}{ Analyte } & \multirow{2}{*}{$\mathrm{pK}_{1}$} & \multirow{2}{*}{$\mathrm{pK}_{2}$} & \multicolumn{2}{|c|}{ pH 7.0} \\
\hline & & & & $\mathrm{RNH}_{2}(\%)$ & $\mathrm{RNH}_{3}+(\%)$ \\
\hline 1 & p-nitroaniline & 1.02 & & 100.0 & 0.0 \\
\hline 2 & o-chloroaniline & 2.66 & & 100.0 & 0.0 \\
\hline 3 & m-chloroaniline & 3.52 & & 100.0 & 0.0 \\
\hline 4 & p-chloroaniline & 3.98 & & 99.9 & 0.1 \\
\hline 5 & m-anisidine & 4.20 & & 99.8 & 0.2 \\
\hline 6 & o-toluidine & 4.45 & & 99.7 & 0.3 \\
\hline 7 & o-anisidine & 4.53 & & 99.7 & 0.3 \\
\hline 8 & o-aminoaniline & 4.61 & 1.81 & 99.6 & 0.4 \\
\hline 9 & $m$-toluidine & 4.71 & & 99.5 & 0.5 \\
\hline 10 & aniline & 4.87 & & 99.3 & 0.7 \\
\hline 11 & m-aminoaniline & 5.01 & 2.56 & 99.0 & 1.0 \\
\hline 12 & $p$-toluidine & 5.08 & & 98.8 & 1.2 \\
\hline 13 & $p$-anisidine & 5.36 & & 97.8 & 2.2 \\
\hline 14 & p-hydroxyaniline & 5.48 & & 97.1 & 2.9 \\
\hline 15 & $p$-aminoaniline & 6.22 & 2.99 & 85.8 & 14.2 \\
\hline
\end{tabular}

Table 5. Percentage of protonated and neutral species at pH 7 [25]

The comparison of the results we have got for all of guest molecules showing the following general tendency: with increase of analyte basicity the response increases. This is truth for all of modified membranes. In most of the cases the isomer para generate the highest response. For another isomers is difficult to estimate with one generate higher signal. In some cases it is isomer ortho, in another meta.

Explanation of weak response of membranes after stimulation with ortho isomers is the possibility to form intramolecular hydrogen bonds.

The correlation between the partition coeffiction of guest (Table 4) and value of potentiometric response is very week. And this suggests that this parameter is rather less important for observed phenomena.

The weakest response we have observed for nitro- and chloro- derivatives of aniline. They are the strongest acids between the investigated compounds.

The main differences between the host molecules under study are structure of upper rim. Ligand 1 poses in their upper rim dihydroxybenzene substituents in which the $\mathrm{OH}$ groups are in position 1, 3 in relation to each other. Because of this distance the intramolecular hydrogen bounds are very week [43]. Additionally this ligand is substituted in position 2 with azonitrobenzene. The presence of this substituent, because of its inductive and rezonance effect causing 
the increase of acidity of phenol groups from upper ring. Ligand 2 contains in its structure dihydroxybenzene with $\mathrm{OH}$ groups in positions 1 and 3.

Next host, number 3, in its upper rim contains the dihydroksybromobenzene. The $\mathrm{OH}$ groups are in position 2, 6 in relation to azabenzene substituent. This substituent, because of its inductive and mesomeric effect, increased the acidity of phenols in relation to previous one.

The upper rim of ligand 4 contains the bromo- 2, 5 hydroksybenzene. The close vicinity of $\mathrm{OH}$ groups creates the very good conditions for creation of intramolecular network of hydrogen bonds [43]. The last ligand (no 5) posses in upper rim trihydroksybenzene. Similarly as in previous one this system allows to create the intramolecular hydrogen bound network.

Comparison of value of potentiometric response we have got for each ligand showing the general tendency which is as follow:

Ligand $1>$ ligand $2>$ ligand 3 , ligand $4>$ ligand 5

This indicates that increase of the acidity of phenols groups in upper rim causing the increase of response value.

The strongest response we have observed for membrane modified with ligand 1 containing in its structure dihydroxybenzene substituted with azonitrobenzene. Acidity of these $\mathrm{OH}$ groups is the highest.

Next in this sequence is ligand 2 substituted with dihydroxybenzene. In this case the acidity of $\mathrm{OH}$ groups is lower in relation to the previous one, but the accessibility of them for guest is much easier. As consequence the creation of hydrogen bound (H......H...N) between host and guest is relatively easy. The next ligand in the discussed sequence, ligand 3 contained in its structure dihydroxybenzene substituted with azobenzene. This causing the increase the acidity of phenolic group in upper rim, but at the same time presence of rather large substituent makes the hindrance in accessibility of $\mathrm{OH}$ groups for guest molecules. The value of generated potentiometric signal is the consequence of these two opposite effects.

Membrane modified with host containing the bromo-derivatives of dihydrobenzene in its structure (no 4) is next in sequence of response value. In this case from one side the inductive effect bromine atom causing increase of acidity of phenolic group and from another one large atom of bromine constitute hindrance in accessibility of phenols groups for guest.

The lowest answer we have got for membrane modified with ligand 5, which poses in its structure trihydroksybenzene. In this ligand the network of intramolecular hydrogen bounds is the strongest. And because of this the formation of supramolecular complex with guest is the most difficult between the ligand under study.

The comparison of lipophilicity of investigated guest molecules showing that there is no direct relation between the lipophilicity of amines and values of signal generated by them.

In order to confirm the supramolecular complex formation between undecylcalix[4]resorcinarene and aniline derivatives at the border of organic/aqueous interface UV-Vis measurements were performed according to procedure reported [52]. 
Upon complexation of para-diaminobenzene, the absorbance decrease at $214 \mathrm{~nm}$, characteristic for UDC[4]Rene was observed. The absorbance at $239 \mathrm{~nm}$ characteristic for para-diaminobenzene also decrease and shifted towards red. Additionally, new peak was visible at $267 \mathrm{~nm}$. These absorbance changes clearly indicated that a supramolecular complex UDC[4]Renepara-diaminobenzene is formed at the membrane surface.

Therefore, it might be concluded that the cationic potentiometric signals observed in the study presented were generated as a result of the supramolecular recognition phenomenon occurring at the organic/aqueous interface.

Based on obtained results and literature data we have proposed the following mechanism of cationic potential signal generation by membranes modified with derivatives of undecylcalix[4]resorcinarene after stimulation with unprotonated derivatives of aminobenzene. In the first step, which is going during the membrane conditioning some of phenolic groups of derivatives of undecylcalix[4]resorcinarene located at the surface of polymeric membranes dissociated and membranes became minus charged. Such type of dissociation of $\mathrm{OH}$ groups of upper rim of undecylcalix[4]resorcinarene was described in [53, 54]. In next step, the network of hydrogen bonds between the derivatives of aminobenzene and phenolic groups is formed. In such situation the amino groups are donors of hydrogen atoms and polarity of them are correlated with acidity of phenol groups. The formation of such network is described in [49-51]. As a result of this, the supramolecular complex of undecylcalix[4]resorcinarene aminobenzene derivatives located at the interface is formed. As a consequence of above complex formation the density of electrons on nitrogen of aminobenzene increases. The measurements were carried out at $\mathrm{pH}$ 7. In this condition all of investigated amines exist in solution mostly as unprotonated compounds (Table 5). The increase of the density of electrons at amine nitrogen atoms causing the increase of their basicity. Because of this, they became protonated in spite of $\mathrm{pH}$ condition in bulk solution. This protonation is done by means of transfer of proton from surface of water face to surface of organic one. The transfer of proton leading to the increase of plus charge of membrane and we can observe the generation of potentiometric cationic signal.

Proposed mechanism is based on the three steps:

The first one concerns dissociation of some phenolic groups from upper rim of investigated ligands.

i. $\quad \mathrm{HostOH}_{\text {membrane }}+\mathrm{H}_{2} \mathrm{O} \leftrightarrow \mathrm{HostO}^{-}+\mathrm{H}_{3} \mathrm{O}^{+}$

Next step consist of transfer of analyte from bulk solution to the interface and formation of supramolecular complex ligand -analyte through hydrogen bonds.

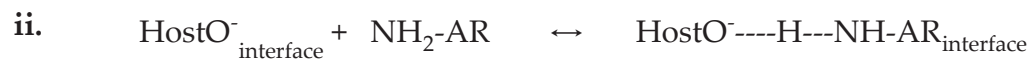

The consequence of this is the increase of basicity on nitrogen atom from supramolecular complex and its protonation.

iii. $\quad \mathrm{HostO}^{-}----\mathrm{H}---\mathrm{NH}-\mathrm{AR}_{\text {interface }}+\mathrm{H}_{3} \mathrm{O}^{+} \leftrightarrow \mathrm{HostO}^{-}----\mathrm{H}^{---} \mathrm{NH}_{2}-\mathrm{AR}_{\text {interface }}^{+}+\mathrm{H}_{2} \mathrm{O}$ 
The formation of such complex at the border we confirmed by means of spectroscopic method. The conformation of first step is based on result we have got for membrane modified with ligand 1 in which the acidity of phenolic groups is the highest.

The results we observed for bromo- and azobenzo- derivatives of investigated undecylcalix[4]resorcinarene showing that the accessibility of phenols groups is very important parameter for intermolecular recognition processes which are going between investigated ligands and analytes.

The weakest response we have observed in case of membranes modified with ligand which has in its structure trihydroxybenzene was explained by possibilities to form the network of intramolecular hydrogen bonds. This is a relatively strong energetic barrier for the described phenomenon.

The second step of proposed mechanism relays on transfer of protons from water phase to organic one. This is supported by fact that independently on the host structure, the strongest signal we have observed for the strongest base between guest compounds under study. The results we have got showed that lipophilicity of analytes it is not crucial parameter.

\section{Conclusions}

We have presented the systematic research on the potentiometric response of membranes modified with macrocyclic compounds containing in their structures amino groups stimulated by the undissociated phenol derivatives and membranes modified with macrocycles containing the phenolic groups stimulated by unprotonated derivatives of aniline.

The results showed that membranes modified with calix[4]pyrrole, calix[4]phyrin and corrole derivatives are able to generate an anionic potentiometric response after stimulation with undissociated forms of phenols derivatives, whereas the membranes modified with undecylcalix[4]resorcinarene derivatives are able to generate the cationic potentiometric response after stimulation with unprotonated aniline derivatives. Our experimental date indicated that in two types of membranes the movement of protons across the interface is responsible for potentiometric signal generation.

The general mechanism of the potentiometric signal generated by membranes modified with discussed host molecules stimulated by uncharged guest relies on:

- the formation of supramolecular host -guest complex at the liquid membrane/water interface

- the transfer of protons from water surface to organic phase surface generated cationic response, whereas transfer of proton from surface of organic phase to the surface of water generate of anionic response.

In both of cases the acidity of host and basicity of guest are crucial parameters for course of processes under discussion. 
- The sensitivity and selectivity of these processes are governed by the acidity of the target molecules studied as well as the ability of host molecules for creation of hydrogen bonds. The lipophilicity of analytes it the secondary parameter.

The described phenomena open the totally new and very promising field of analytical application of potentiometric method.

\section{Author details}

Jerzy Radecki* and Hanna Radecka

*Address all correspondence to: j.radecki@pan.olsztyn.pl

Institute of Animal Reproduction and Food Research of Polish Academy of Sciences, Olsztyn, Poland

\section{References}

[1] Bakker, E., Talanta, 2004, 63, 21.

[2] Gale, P.A., Coordination Chemistry Reviews , 2003, 240, 191.

[3] Umezawa Y., "Ion-Selective Electrodes" , in "Encyclopedia of Supramolecular Chemistry", 2004, Marcel Dekker, New York, p.747.

[4] Ito, T., Radecka, H, Tohda, K., Odashima, K., Umezawa,Y. J. Am. Chem. Soc. 1998, 120, 3049.

[5] Odashima , K., Naganava, R., Radecka, H., Kataoka, M., Kiura, E., Koike, T., Tohda, K., Tange, M., Furta, H., Sessler, J. L.,. Yagi, K., Umezawa, Y. Supramolecular Chemistry 1994, 4,101 .

[6] Ito, T., Radecka, H., Umezawa, K., Kiura, T., Yashiro, A., Lin, X., Kataoka, M., Kiura, E., Sessler, J.L., Yagi, K., Umezawa, Y. Anal. Sciences. 1998 14, 89.

[7] M. De Serio H. Mohapatra, R. Zenobi, V. Deckert, Chemical Physics Letters 417 (2006) $452-456$

[8] Russell, E., Morris Nature Chemistry 2011, 3, 347-348.

[9] Spichiger -Keller U.E., "Chemical Sensors and Biosensors for Medical and Biological Applications" , 1998, Wiley-VCH, Weinheim, Germany.

[10] Pretsch, E., Bühlmann, P., Bakker, E., Chem Rev., 1997, 97, 3083; 1998 , 98, 1593.

[11] L. Bulgariu, H. Radecka, M. Pietraszkiewicz, O. Pietraszkiewicz, Analytical Letters, 2003, 36, 1325-1334. 
[12] Radecka, H., Szymañska, I., Pietraszkiewicz, M., Pietraszkiewicz, O., Aoki, H., Umezawa, Y. Chem. Anal. (Warsaw), 2005, 50, 85-102.

[13] Szymañska, I., Radecka, H.,.Radecki, J., Gale, P.A., Warriner, C.N. Journal of Electroanalytical Chemistry, 2006, 591, 223-228.

[14] Radecki, J., Stenka, I., Dolusic, E., Dehaen, W., Plavec, J. Comb. Chem. High. Throughput Screening 2004, 7,375-381.

[15] Radecki, J. Radecka , H., Current Topice In Electrochemistry, 2008, 13, 27-35.

[16] Piotrowski, T., Radecka, H., Radecki, J., Depraetere, S., Dehaen, W. Electroanalysis 2001, $13,342-346$.

[17] Radecki, J., Radecka, H., Piotrowski, T., Depraetere, S., Dehaen, W., Plavec, J. Electroanalysis 2004, 16, 2073-2081.

[18] Szymañska, I., Orlewska, Cz., Janssen, D., Dehaen, W., Radecka, H. Electrochimica Acta 2008, 53, 7932 - 7940.

[19] Piotrowski, T., Radecka, H., Radecki, J., Depraetere, S., Dehaen, W., Material Science and Engineering 2001, 18, 223-228.

[20] Piotrowski, T., Radecka, H., Radecki, J., Depraetere, S., Dehaen, W., Anal. Letters 2002, 35, 1895-1906.

[21] Radecki, J., Stenka, I., Dolusic, E., Dehaen, W., Electrochimica Acta 2006, 51, 2282-2288.

[22] Saraswathyamma, B., Pająk, M., Radecki, J., Maes, W., Dehaen, W., Kumar, K.G., Radecka, H. Electroanalysis, 2008, 20, No. 18, 2009 - 2015.

[23] Saraswathyamma, B., Grzybowska, I., Orlewska, Cz., Radecki, J., Dehaen, W., Kumar, K.G., Radecka, H. Electroanalysis, 2008, 20, No. 21, 2317-2323.

[24] Ocicka, K., Radecka,H., Radecki, J., Pietraszkiewicz, M., Pietraszkiewicz O. Sensors and Actuators B, 2003, 217-224.

[25] Poduval, R.,. Kurzątkowska, K., Stobiecka, M., Dehaen, W.F.A., Dehaen, W., Radecka, H., Radecki, J. Supramolecular Chemistry, 2010, 22, No. 7-8, $412-418$.

[26] Gale, P., A., Anzenbacher Jr, P., Sessler, J., L., Coordination Chemistry Reviews, 2001, 222, 57.

[27] Sessler, J. L., Camiolo, S., Gale, P. A., Coordination Chemistry Reviews, 2003, 240, 17.

[28] Custelcean, R., Delmau, L.H., Moyer, B.A., Sessler J.L., Cho, W.S., Gross, D., Bates, G.W., Brooks, S.J., Light, M.E., Gale, P.A., Angew. Chem., 2005, 117, 2593.

[29] Gale, P.A., Sessler, J.L., Král, Lynch, V., J. Am. Chem.Soc., 1996, 118, 5140.

[30] Bucher, Ch., Zimmerman, R.S., Lynch, V., Kral, V., Sessler, J. L., J.Am.Chem Soc 2001, 123, 2099-2100. 
[31] Camiolo, S., Coles, S.J., , Gale, P.A., Hursthouse, M.B., Sessler, J.L., Acta Crystallogr. Sect. E, 2001, 75, 816 .

[32] Mahammed, A., Weaver, J.J., Gray, H. B., Abdelas , M., Gross, Z., Tetrahedron Letters, 2003, 44, 2077.

[33] Jonson, A., W,. Kay, I.T. J. Chem. Soc. 1965, 1620.

[34] Broadhurst, M.J., Grieg, R., Shelton, G., Johson, A.W. J. Chem.Soc. Perkin Trans I 1972, 143.

[35] Wroński, M. J., Chromatogr. A, 1997 , 772, 19.

[36] Dimitrienko, S.G., Myshak, E. N., Pyatkova, L. N., Talanta , 1999, 49, 309.

[37] Leo, A., Hansch, C., Elkins, D., Chem Rev. 1971, 71, 525.

[38] Piotrowski, T., Szymańska, I., Radecka, H., Radecki, J., Pietraszkiewicz, M., Pietraszkiewicz, O., Wojciechowski, K., Electroanalysis , 2000 , 12, 1397.

[39] Szymańska, I., Radecka, H., Radecki, J., Pietraszkiewicz, M., Pietraszkiewicz, O., Combinatorial Chemistry \& High Throughput Screening , 2000, 3, 509.

[40] Szymańska, I., Radecka, H., Radecki, J., Pietraszkiewicz, M., Pietraszkiewicz , O. Electroanalysis , 2003 , 15, 294-302.

[41] Asokan, C.V., Smeets, S., Dehaen, W., Tetrahedron Lett., 2001, 42, 448.

[42] Stenka, I., Radecka, H., Radecki, J., Dolusic, E., Dehaen, W. Pol. J. Food Nutr. Sci., 2003, $53,127$.

[43] Aakeröy, C.B., Seddon, K.R., Chem. Soc. Rev., 1993, 22,397-407.

[44] Tohda, K., Higuchi, T., Dragoe, D., Umezawa, Y., Analytical Sciences, 2001, 17, 833.

[45] Amemiya, S., Bühlmann, P., Pretsch, E., Rusterholz, B., Umezawa, Y., Anal. Chem. 2000, 72,1618

[46] Bühlmann, P., Yajima, S., Tohda, K., Umezawa, K., Nishizawa, S., Umezawa, Y., Electroanalysis, 1995, 7, 811

[47] Chaniotakis, N., Chasser, A., Meyerhoff, M.E., Grovers, J. Anal. Chem. 1988, 60, 185.

[48] Kibbey, C.E, Park, S.B., DeAdwyler, G., Meyerhoff, M.E., J Electroanal. Chem., 1999, 335 135-194.

[49] Woods, C.J., Camiolo, S., Light, M.E., Coles, S.J., Hursthouse, M.B., King, M.A., Gale, P.A., Essex, J.W., J. Am. Chem. Soc., 2002, 124, 8644.

[50] Beer, P.D., Cadman, J. Coord. Chem. Rev. 2003, 240, 131- 155.

[51] Ammico, D.A, Di Natale, C., Polasse, R., Macagnanon, A., Mantini A. Sens. Actuator B 2000, 65, 209-215. 
514 An Integrated View of the Molecular Recognition and Toxinology - From Analytical Procedures to Biomedical Applications

[52] Kurzatkowska, K., Radecka, H., Dehaen, W., Wasowicz, M., Grzybowska, I. J. Comb. Chem. Throughput. Screen. 2007, 10, 604-6010.

[53] Akecylan, E., Bahidir, M., Yilmaz, M.J. Hazard. Mater. 2009, 162, 960-966.

[54] Gustasche, C. D., Iqbal, M., Alam, I. J. Am. Chem. Soc. 1987, 109, 4314-4320. 